\title{
The In-Formed Glitch and Its Tools for Generating Digital Architectural Form
}

\author{
Yusur Raed Mohsen *, Basim Hasan Hashim \\ University of Technology, Baghdad, Iraq
}

Received October 12, 2021; Revised January 20, 2022; Accepted February 8, 2022

\begin{abstract}
Cite This Paper in the following Citation Styles
(a): [1] Yusur Raed Mohsen, Basim Hasan Hashim, "The In-formed Glitch and Its Tools for Generating Digital Architectural Form," Civil Engineering and Architecture, Vol. 10, No. 2, pp. 632-643, 2022. DOI: 10.13189/cea.2022.100219.

(b): Yusur Raed Mohsen, Basim Hasan Hashim (2022). The In-formed Glitch and Its Tools for Generating Digital Architectural Form. Civil Engineering and Architecture, 10(2), 632-643. DOI: 10.13189/cea.2022.100219.
\end{abstract}

Copyright $\mathrm{C} 2022$ by authors, all rights reserved. Authors agree that this article remains permanently open access under the terms of the Creative Commons Attribution License 4.0 International License

\begin{abstract}
After the development of technology and the technological participation into the world of architectural design instead of the traditional methods that designers used to create shapes, the trend began to use the computers and architectural design software programs instead. This leads to a flaw in the architectural design rather than limiting it to the artistic side to generate architectural forms characterized by aesthetics and uniqueness. The glitch reveals a new opportunity and a spark of creative energy indicating that something new is about to be created. Therefore, the research problems are lack of knowledge in the in-formed glitch and the tools that are invested by architects to generate the architectural forms. The aim of the research is to find the tools that generate digital architectural forms through the in-formed glitch, as well as, study the two types of glitch (given and in-formed) and the glitch in architecture design. The practical application on some projects shows that one of the most important glitch tools designers relied on to reach architectural forms with unique aesthetic shapes that are characterized by dominance, transparency and balance. It expresses the aesthetic aspects in unexpected way that makes the recipient feel shocked when he sees the output for the first time, then multiple interpretations explaining the beauty in the eyes of the beholder depending on his cultural background.
\end{abstract}

Keywords Glitch, The Given Glitch, The In -Formed Glitch, Digital Architecture

\section{Introduction}

The technological development led to discover new aesthetic style resulting from computer errors and gaps that occur in computer digital algorithms. Thus new aesthetic theory emerged as a reaction to previous aesthetic theories giving the sense of beauty using glitch and its tools to generate new digital architectural forms. This research deals with given, in-formed glitch and shows the lack of knowledge about the concept of in-formed glitch and its tools that could be used to generate the digital architectural forms. This research will clarify glitch, its relative types, definitions, and tools for generating the digital architectural form through the concept of in-formed glitch and practical application on selected projects to reach the final results and conclusions.

\section{Defining the Glitch}

Glitch can be defined as an algorithm phenomenon that behaves unexpectedly for the programmer or viewer, it occurs at a certain moment that leads to a change in the algorithm producing unexpected results [1].

\section{Glitch in philosophy:}

It is a technological thinking, and it is also can be a base for the social construction, in fact glitch takes a position between these two thoughts [1].

The researchers define glitch as: an algorithm phenomenon that behaves in unexpected way for the viewer, it happens shortly as a transient error in the program. This 
term is particularly common in the computing and electronics industries, as well as among video game players and more recently used in the field of architecture.

\section{Glitch in Architecture and the H3333333k Approach}

Glitch in architecture: It is a new possibility within digital architecture that is able to deal with complex designs in a more open manner. This can be done by distorting the image data to produce new images. Therefore, data appears in a way that shows how it has been changed. It also reveals new opportunity and, a spark of creative energy indicating that something new is about to be created. Glitch has no solid form or state through time that is often seen unexpected and abnormal mode of action, where glitch is used to deconstruct the myth of linear progress and what is known as the perfect technology.

After the glitch concept has been expanded to include similar systems, for example, genetic mutation or building failure is often referred to as a natural glitch. This scale should be used carefully to separate between the glitch and errors because glitch can be handled and controlled, on the opposite site errors cannot be couldn't be controlled [2].

The H3333333k approach highlights the same problems within the context of architecture, where the House of Electronic arts Basel (HeK) facade is designed by taking an image of the existing facade, twisting the data to the jpeg image and then reconfiguring the original interface to resemble the curved data. For photography, Figure 1 [3].

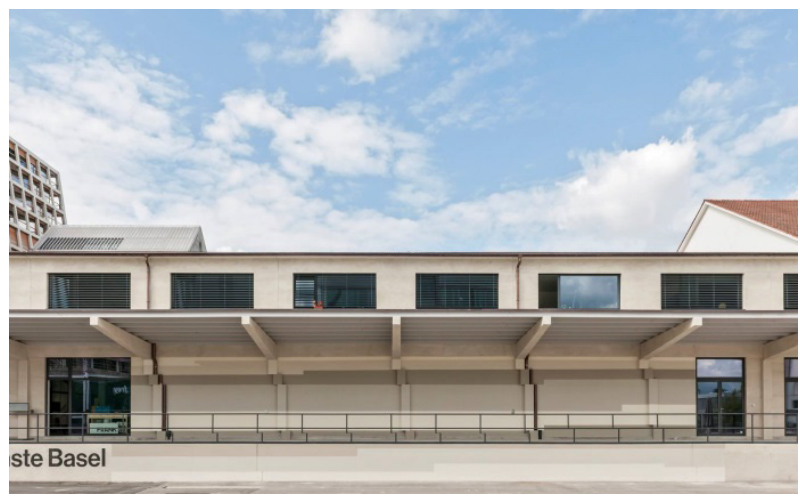

Figure 1. Facade of the House of Electronic arts Basel (HeK)

The house of Electronic arts located in Switzerland is a place for creative and critical discourse on the aesthetic, socio-political and economic impact of media technologies" (HEK, 2016) Designers '! Mediengruppe Bitnik' applied a digital image error directly onto the facade of the original building and consequently physically built exactly this. The designers feel the glitch "misaligns the elements of the facade, bringing disturbance to an otherwise settled structure". This is an attempt to express glitch in a $3 \mathrm{~d}$ physical environment. However, the interpretation is ultimately still read as a corrupt flat image further so viewing this architecture over the internet it is read through angled 2D photographs with the facade of the building presented convincingly as a corrupted $2 \mathrm{~d}$ image leading some to believe it is simply a website error, misconstruing the glitch in the fixed architecture all together [4].

\section{The Given Glitch and the In-Formed Glitch}

At the beginning, glitch was known as "given glitch" which is usually found on a grid that contains pixels distributed and divided individually in a two-dimensional image. This thought led the designers to invest the given glitch, and use it in the third dimension which is known after that as an in-formed glitch. Table 1 [5].

Glitch gives the opportunity to clarify the shapes on the third - dimensional level that is made in computer by considering the design capabilities of architectural designer and ability to use the computer to express it. Also, he must consider to maintain the originality of the initial information in the file before recycling it from a given to in - formed glitch. Or before any changes happen on it, the architectural design that is done by using the computer gives the ability to react with the current technologies in an adaptive and responsive way [6].

Table 1. The given glitch and in - formed glitch

\begin{tabular}{|c|c|}
\hline The in - formed glitch & The given glitch \\
\hline $\begin{array}{c}\text { Humanizing it where human } \\
\text { intervention takes place }\end{array}$ & $\begin{array}{c}\text { It occurs as a result of } \\
\text { collecting the information in } \\
\text { one place more than the other }\end{array}$ \\
\hline $\begin{array}{c}\text { The beauty of in-formed glitch } \\
\text { lies in controlling it to produce } \\
\text { different and distinct outputs }\end{array}$ & $\begin{array}{c}\text { The beauty of given glitch lies } \\
\text { in producing unique outputs by } \\
\text { chance in unexpected way }\end{array}$ \\
\hline
\end{tabular}

From the above, it appears that the glitch aesthetics process exploits the instantaneous transformation of binary information. This new method for exploration with in the digital architecture is linked to algorithm which results in the given glitch, where the designer intervention adds the humanization touch on the architectural design that is made by computer. Therefore, it is an essential interaction element in the design, which produces in- formed glitch that's what the research seeks to clarify.

The main research vocabularies are glitch, given glitch, in- formed glitch, digital architecture and the tools of generating the digital architectural form through the concept of glitch. From the previous studies related to glitch, we figured the following:

(1) Glitch is one of the methods by that creative original forms are produced by humanizing production.

(2) The design has two directions from actual reality to virtual reality and then from virtual reality to actual reality.

(3) Glitch is used as a basic starting point in the design method. It also emphasizes the participation of recipients to generate new forms. 
(4) The in - Formed glitch is a new way of using media, and glitch is an essential part of our world and not just an auxiliary element for a new aesthetic theory and can be used as part of a creative process through scientific invention and innovation. Accidents, errors and glitch are essential to the progress of science and the development of mankind.

(5) Glitch is a final result of digital decay processes to generate outputs that carry the esthetic standards of digital architecture.

\section{Literature Review}

\subsection{Mankman, Rosa, the glitch moment (um), 2011 [7].}

The study states that error isn't a sign of improper outputs. When the source of the noise effect is not yet known, the noise becomes confusing. In the digital world, this type of noise is often referred to "glitch". It is an unexpected event, unintended consequence, break or disorder in a system, individually, and that is precisely its conceptual strength and dynamic contribution to media theory. From an informational (or technical) perspective, it is best to consider glitch as a single fracture of the data flows programmed within a technological system.

Because of the essential nature of images and their relationship to pure error in terms of process and viewer perception, Manknman felt the need to compose a word that appropriately describes the similarity of this instrument to actual disorder and present it as a distinctly separate entity. Thus, the term "Glitch-alike" came to fulfill this role. Glitch-alikes are a collection of digital new pieces that resemble visual aspects of real trouble spots in their original habitat, Table 2.

Table 2. The pure glitch and the glitch - alike

\begin{tabular}{|c|c|}
\hline glitch - alike & pure glitch \\
\hline 1- Intentionally & Accidently \\
\hline 2- planned & 2- It happens by chance \\
\hline 3- It is configured intentionally & 3- Produces without permission \\
\hline 4- designed & 4- exists \\
\hline 5- artificial & 5-real \\
\hline
\end{tabular}

\subsection{Heijer, Eelco den, Evolving Glitch Art, April, 2013.} [8]

This study dealt with the art of glitch as a new representation in the evolutionary art. It referred that glitch art is a modern form of digital art, and the term glitch is a general term for a variety of techniques that digitally manipulate images by changing their digital encoding in an unconventional way, like gif or jpeg. By applying one or more glitch processes, this glitch recipe represents the genotype in the evolutionary art system. Thus introducing glitch processes, genotypes, crosses, and mutations. The glitch process may cause the image to be broken and encoded. Thus, calculations for the rate of damage for each glitch process, and sometimes the glitch leads to appearance of an image that is visually similar to the original image. They studied of the visual effect of each glitch process, which was also calculated and showed the use of glitch producing new genotype of image in the international art.

The study also mentioned the tools of generating the glitch shape through (deletion, addition, inversion, substitution, intersection, mutation) using them a new pattern of disorder to generate an outcome characterized by creativity and uniqueness.

\subsection{Vuillemot, Huron, Glitches as a Generative Design Process, 2016. [9]}

The study focused on understanding and interpreting the meaning of glitch in a conceptual context of information by collecting examples of glitch on social media that are collected according to the visual and semantic similarities. The observer behind the cases of such errors remain so far difficult and unknown to the innovator because it remains unknown. However, they used reverse engineering in synthetic ways to discuss the glitch from the aesthetic and expressive aspects.

They dealt with the types of glitch and identified them with the following points:-

(1) Glitch in the texts.

(2) Glitch resulting from drawings, sketches, and graphs.

(3) Visual glitch.

(4) Glitch caused by texture and noise.

(5) Artistic memories.

(6) Short Story glitch (P.3-4-5).

From all the foregoing, the following table can be deduced table (3).

\section{Selection Criteria for the Selected Projects}

In order to test the glitch in digital architecture as a strategy to generate and, discover the digital form according to the tools of glitch in general and the tools of in- formed glitch in particular, projects were selected according to the following criteria:-

(1) The selected projects include glitch in one of its aspects (the given, the in- formed)

(2) The selected projects must have innovative and original product, which can be reached by obtaining distinct and modern samples.

(3) Using advanced digital technology to generate and, find the shape.

(4) The selected projects must contain integration between the advanced digital tools and, the different engineering majors.

(5) These projects should belong to different architects and follow the trend of modern digital architecture. 
(6) Diversity and difference of projects, also different cultural identity.

(7) Multiplicity and functional variance of projects to test glitch on several levels (2d-3d).

\section{Measuring Method}

The paragraph explains measurement method that will be followed in the elected projects, and their variables, by a qualitative measurement method. The amount of achievement of the elected project through direct notation of the word $(1=$ realized value, $0=$ unrealized value) to extract verification ratios. It is then used to know the impact of vocabulary and its effectiveness in generating glitch shapes in digital architecture, using Excel program to analyze the results. Thus, extracting the percentage to the amount of achievement of the item in the project by adopting the following formula:

\section{Percentage $(\mathrm{P})=($ Number of Repetitions of an Item $(\mathrm{Fi}) /$} Sample Size $(\mathrm{N})) * 100$

This method aims to know the effectiveness of the glitch vocabulary of glitch in the architectural design process and, the role of design mechanisms that lead to formation glitch shapes.

\section{Description of the Selected Projects}

This paragraph included a general description of the elected projects by presenting the available information about those three architectural projects that deal with glitch on the third dimension (3D) with different types of glitch and were coded as research samples for measurement purposes, table 4 shows of those projects.

Table 4. Elected projects

\begin{tabular}{|c|c|c|c|}
\hline $\begin{array}{c}\text { The } \\
\text { code }\end{array}$ & $\begin{array}{c}\text { Glitch } \\
\text { type }\end{array}$ & Project name & level \\
\hline A & Visual glitch & $\begin{array}{c}\text { Pixel Tower or } \\
\text { Mahanakhon- 2016 }\end{array}$ & 3D \\
\hline B & $\begin{array}{c}\text { Glitch caused by } \\
\text { noise }\end{array}$ & $\begin{array}{c}\text { WAA-affiliated Yinchuan } \\
\text { Museum of Contemporary } \\
\text { Art - 2016 }\end{array}$ & 3D \\
\hline C & $\begin{array}{c}\text { Glitch caused by } \\
\text { texture }\end{array}$ & The glitch House & 3D \\
\hline
\end{tabular}

Table 3. Generating architectural form through turbulence formed

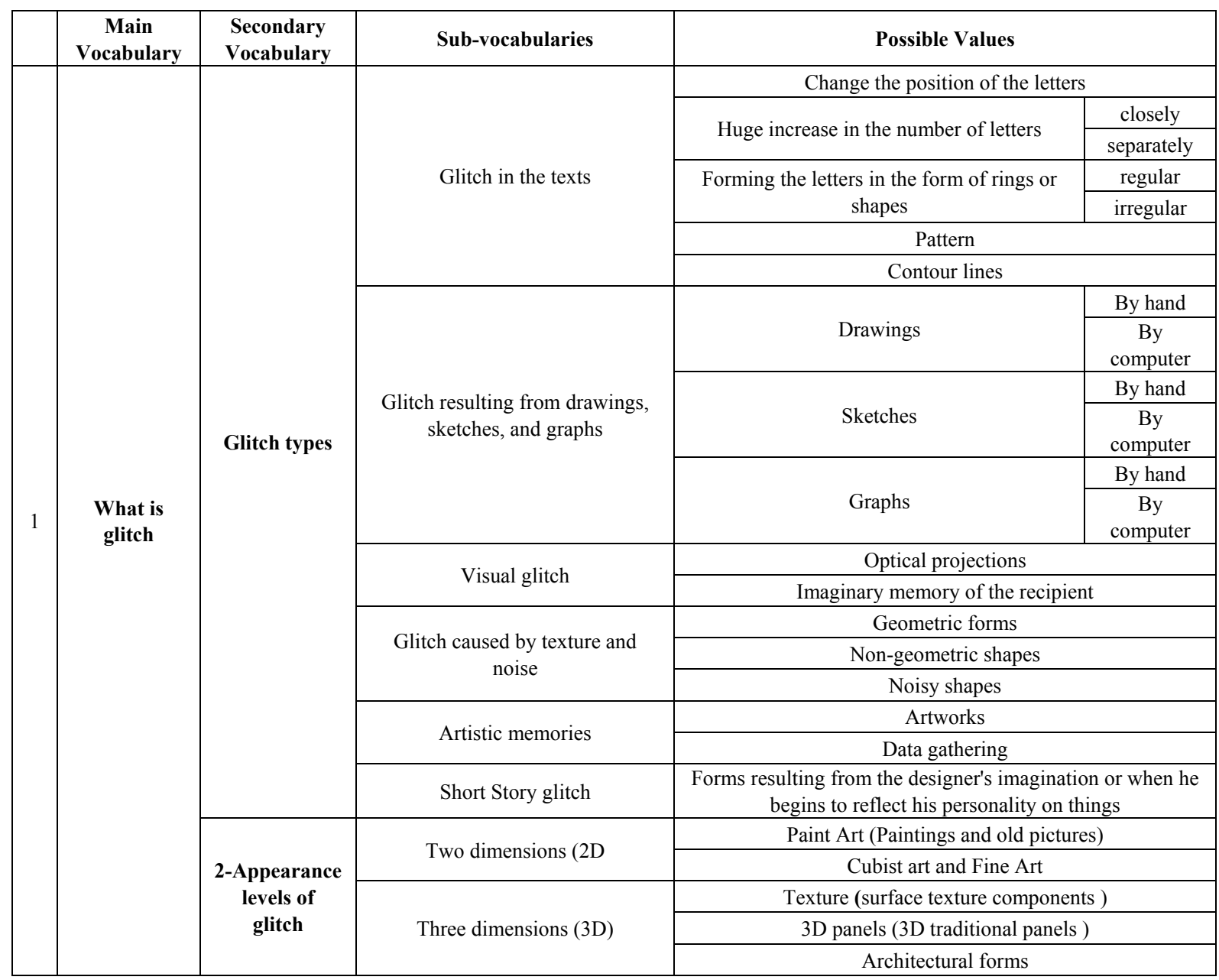


Table 3. Continued

\begin{tabular}{|c|c|c|c|c|c|}
\hline & & & & Decon & tems \\
\hline & & & Decrease & Changing the positiol & e geometric shapes \\
\hline & & & & Abstract & shapes \\
\hline & & & Dariotion & Organiz & iation \\
\hline & & & Deviationit & Disorde & viation \\
\hline & & & & & \\
\hline & & & Translation & & \\
\hline & & & & Archite & shape \\
\hline & & & & & \\
\hline & & & Abstraction & & \\
\hline & & & Austiaction & Extract some sid & remove the rest \\
\hline & & & & The displacem & some masses \\
\hline & & & & & \\
\hline & & & Scaling & & \\
\hline & & & & Archite & shape \\
\hline & & & & Dividing the & nto squares \\
\hline & & & Dividing the mass & Dividing the $\mathrm{n}$ & to rectangles \\
\hline & & & & Coding & cture \\
\hline & & & & Data c & ssion \\
\hline & & & Codino & Correctir & mistake \\
\hline & & & - venting & Encry & code \\
\hline & & & & Code the & ind data \\
\hline & & & & Shifting from fragı & ion to integration \\
\hline & Tools & Tools of the in - & & & System properties \\
\hline 2 & generating & formed & & The level of complexity & The environment \\
\hline & glitches shape & glitch & Complexity & depends on & $\begin{array}{l}\text { The nature of the } \\
\text { interaction between its } \\
\text { components }\end{array}$ \\
\hline & & & & Complexity in the shape & fractional \\
\hline & & & & system & non-linear dynamics \\
\hline & & & & & \\
\hline & & & & Disc & \\
\hline & & & & & \\
\hline & & & Donatition & & \\
\hline & & & 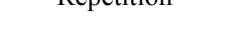 & & \\
\hline & & & & & \\
\hline & & & & & \\
\hline & & & & & \\
\hline & & & & Divide & cture \\
\hline & & & & Paste the pictu & nother place \\
\hline & & & Division & & \\
\hline & & & & Contrast in color be & two different areas \\
\hline & & & & Change the & extension \\
\hline & & & & Incorrect pixel ( & ect pixel inset) \\
\hline & & & Pixilation & Bend data $(\mathrm{Ch}$ & ata locations) \\
\hline & & & & Change data (Remove so & formation about pixels) \\
\hline & & & & Manipulat & methods \\
\hline & & & Data maninulation & Manipulatic & protocols \\
\hline & & & Data mampuration & Convert an & fy the file \\
\hline & & & & Distorte & entry \\
\hline
\end{tabular}




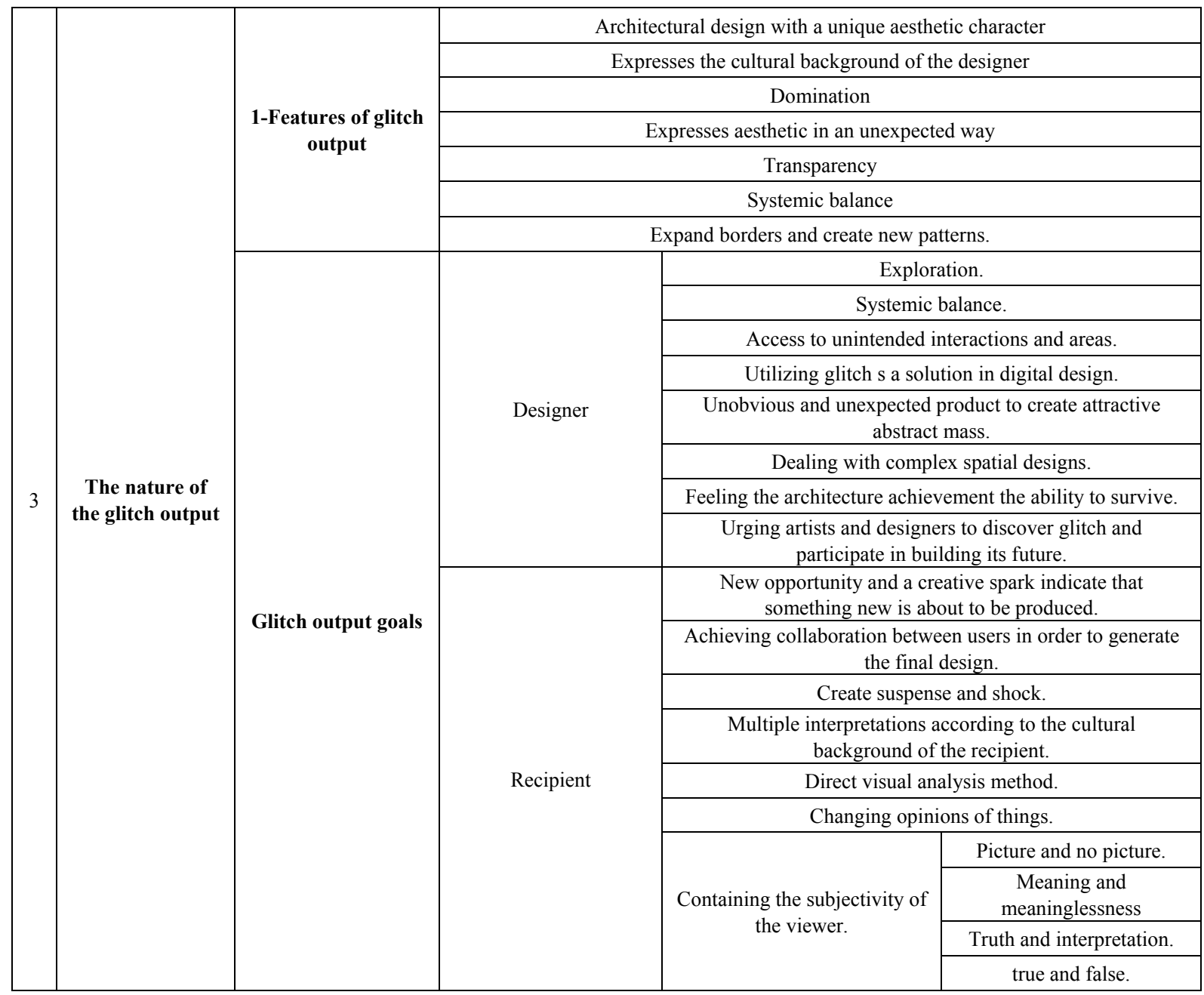

\subsection{Pixel Tower or Mahanakhon- 2016}

The building is considered one of the international designs of skyscrapers in Bangkok, Thailand. The building looks amazing from all angles, its height is 314 meters, making it taller than the Eiffel Tower, also considered as one of the tallest tower in Thailand, exceeding the Baiyoke Tower, which is 304 meters high. The building has 77 floors it contains residential areas, and commercial areas as well, which includes bars, and restaurants. Figure 2 [11].

This building represents the evolution of Bangkok, moving away from the traditional design process of skyscrapers. Instead of producing an organic form, this exceptional form was created to be a monumental skyscraper in the center of Bangkok. Concentrating on the distinctive design and lighting system [10].

This tower shows glitch through the helix shape that is wrapped around the cubic shape in a pixelated manner. By removing and dividing some blocks and changing their positions, the designer gave transparency, attractiveness, and dominance to the building by highlighting the interior of building. Figure 3 table 5 [12].

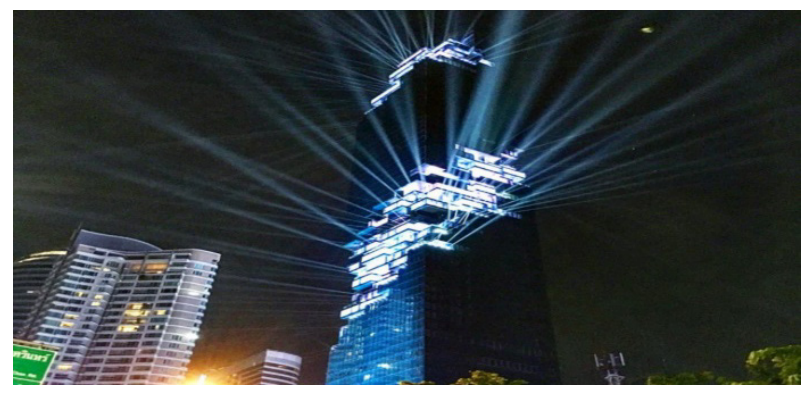

Figure 2. Pixel Tower
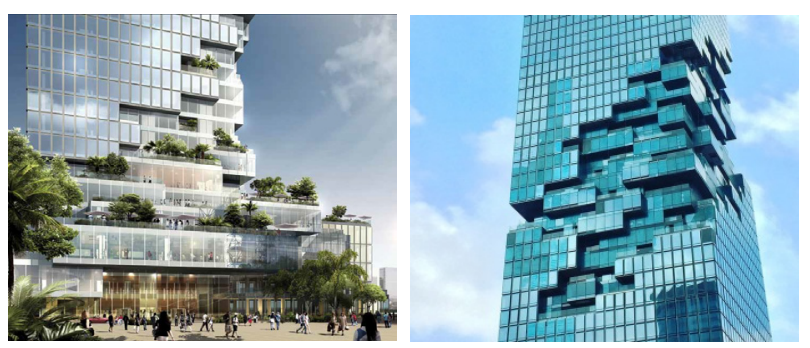

Figure 3. The pixels from the bottom to the top of the tower 
Table 5. Project information

\begin{tabular}{|c|c|}
\hline Project name & Pixel Tower or Mahanakhon \\
\hline Designer & PACE Development Corporation Plc \\
\hline Location & Thailand (Bangkok) \\
\hline Classification & Skyscraper \\
\hline Glitch type & Visual glitch \\
\hline Glitch level & 3D level \\
\hline $\begin{array}{c}\text { Glitch } \\
\text { mechanisms }\end{array}$ & $\begin{array}{c}\text { Decrease, pixilation, Dividing the mass, } \\
\text { Translation, Scaling, Abstraction, Repetition, } \\
\text { data manipulation }\end{array}$ \\
\hline
\end{tabular}

8.2. WAA-affiliated Yinchuan Museum of Contemporary Art - 2016

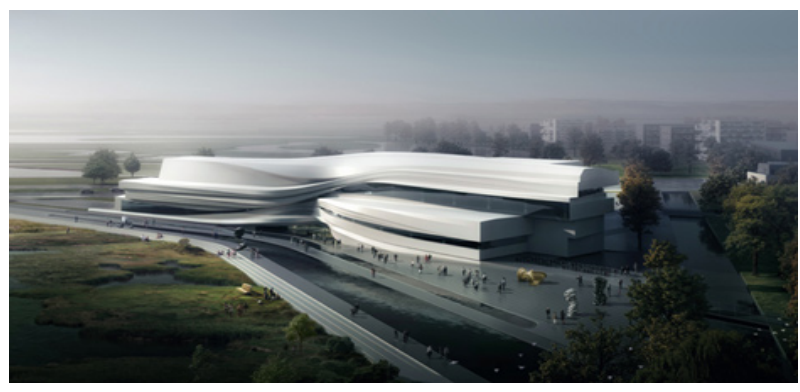

Figure 4. Affiliated Yinchuan Museum of Contemporary Art

The Yinchuan Museum in China is one of the winning projects in the annual Emerging Architecture Awards. At first glance, the museum appears to be intended as a familiar architectural discourse, but in fact it is not. In other words, it is an unexpected product with attractive abstract pieces to create suspense and astonishment for the recipient. The smooth tectonic lines make it a controversial, unique architectural building. Also the radical departure from the dominant design methodology is visible. Figure 4. [13].

The design was spired by the topography, where 1,600 panels of glass-reinforced concrete GRC used to create smooth curves of the facade that is shown on the three floors of galleries, classrooms, library and theater of the building. To present glitch according to design concept, the design model was analyzed in computer, each panel was manufactured separately then it was collected on site to create a smooth finish. Exterior design has a special expression of its own containing vocabulary of contrasts, singularities, folds, cracks, glitches, and highly customized design approach Figure 5. In contrast to the interior design of the building, which is characterized by clarity and simplicity in the main foyer that connects the two main entrances and exhibition halls, the design focused on differentiation rather than symmetry and glitch rather than continuity and, craftsmanship rather than repeated digital industrial production. And, sudden glitch instead of the continuous signal makes the building a proposal Unique intellectual and artistic Figure 6, table 6 [13].
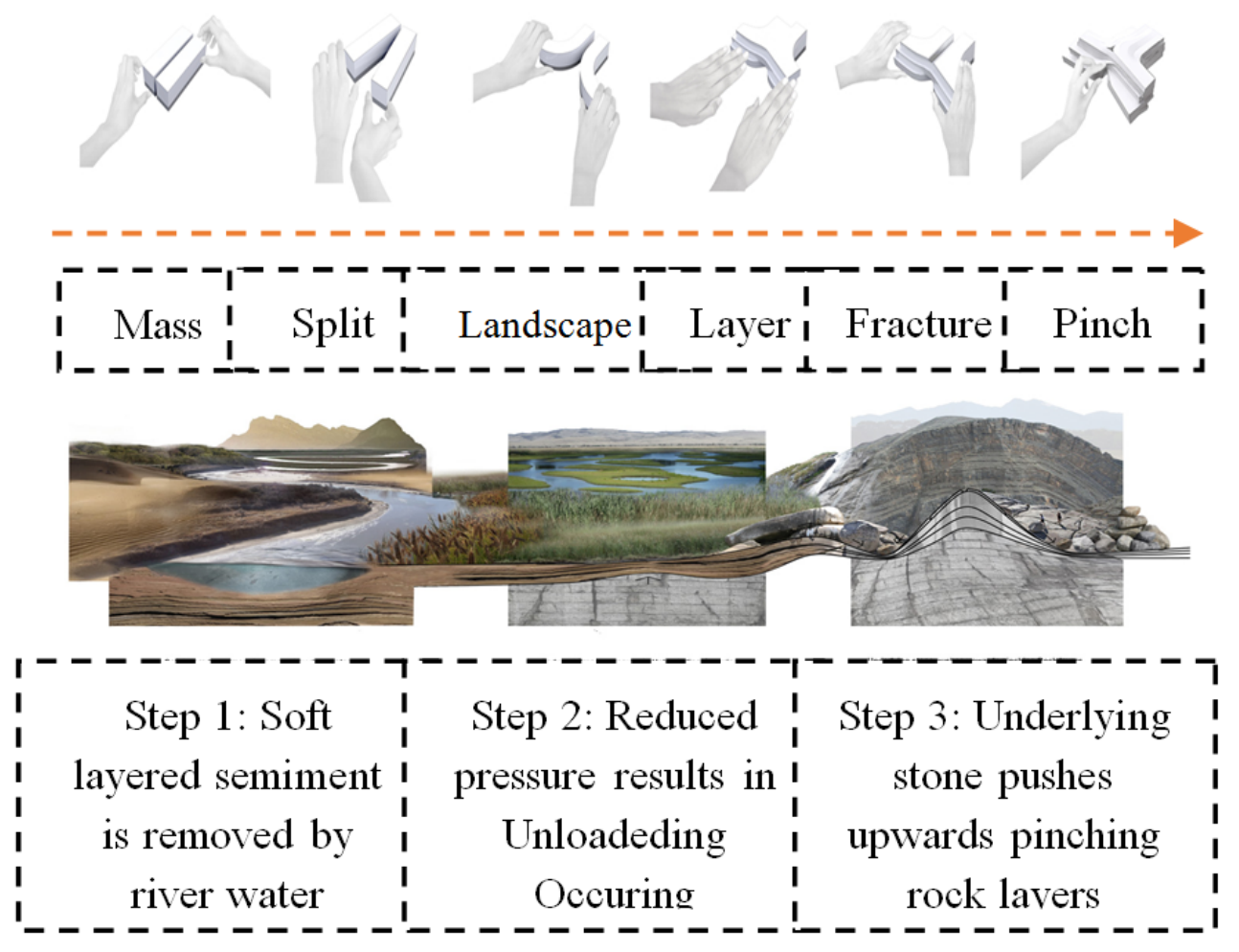

Figure 5. Shape formation steps 


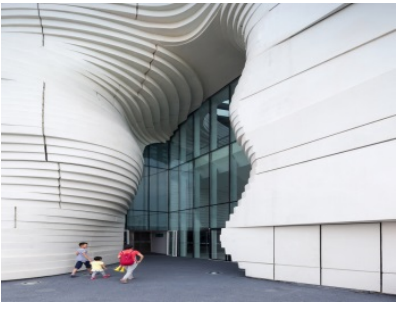

B

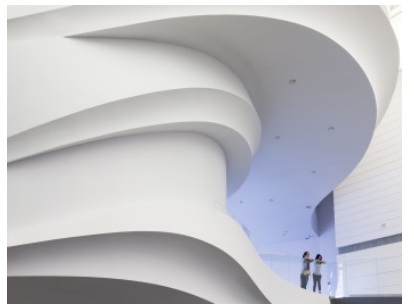

A
Figure 6. A: interior design; B exterior design

Table 6. Project information

\begin{tabular}{|c|c|}
\hline Project name & $\begin{array}{c}\text { WAA-affiliated Yinchuan Museum of } \\
\text { Contemporary }\end{array}$ \\
\hline Designer & WAA (We Architect Anonymous) \\
\hline Location & China (Yinchuan ) \\
\hline Classification & Museum \\
\hline Glitch type & Glitch caused by noise \\
\hline Glitch level & 3D level \\
\hline $\begin{array}{c}\text { Glitch } \\
\text { mechanisms }\end{array}$ & $\begin{array}{c}\text { Decrease, Abstraction, Dividing the mass, } \\
\text { Complexity, Scaling, Division, Repetition, data } \\
\text { manipulation }\end{array}$ \\
\hline
\end{tabular}

\subsection{The Glitch House}

It is located near the beach of Playa Grande in the Dominican Republic, 1650 square feet with 3 bedrooms, 2 bathrooms, kitchen, living areas and, 330 square feet of accessible roof garden. The house returns to a secluded location away from its neighbors and hides in a semi-forest, shades with a roof garden. Projects like these try to fit into their context, but in this project there is a new and interesting interpretation of the site. It combines a certain digital sensibility with ultra-simple craftsmanship on the designer's hand. Structurally, the housing type is somewhat traditional for the tropics. Figure 7, the building is made of stacked concrete building blocks. However, the method of its deployment is new where the facades are rotated by 45 degrees to form a series of irregular volumes and the blocks are overlapping to create a gradient and turbulent three-dimensional pattern on those facades [14].
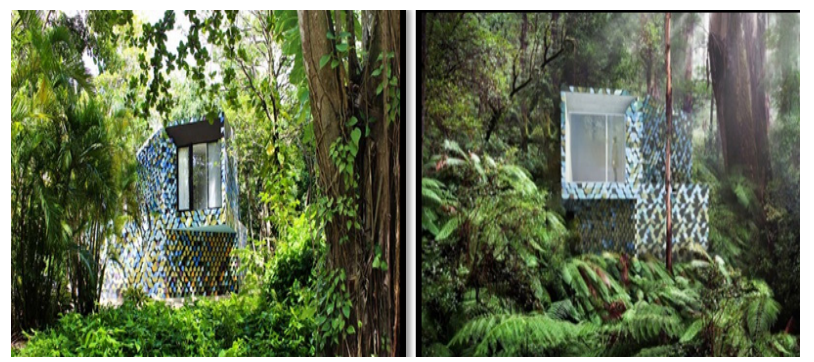

Figure 7. Glitch house

The cladding is perhaps most exciting of all. Handcrafted Cement slabs stuck together in a quarter arc of bright color against a dark background and arranged in mysterious floral patterns, cover the house with dazzling mosaics of blue, green and orange. Thus making it seem almost shimmering in the shadows the unfinished forest. Inspired by the bright colors and organic shapes of the forest itself, the cladding is not applied uniformly or arbitrarily to the outside, but assumes distinctive formations around doors, windows and other features. This was done using architectural programs by the designer after entering a number of data a way that ensures the production of this unique product, changing the views of things for the recipient Figure 8 table 7 [13].
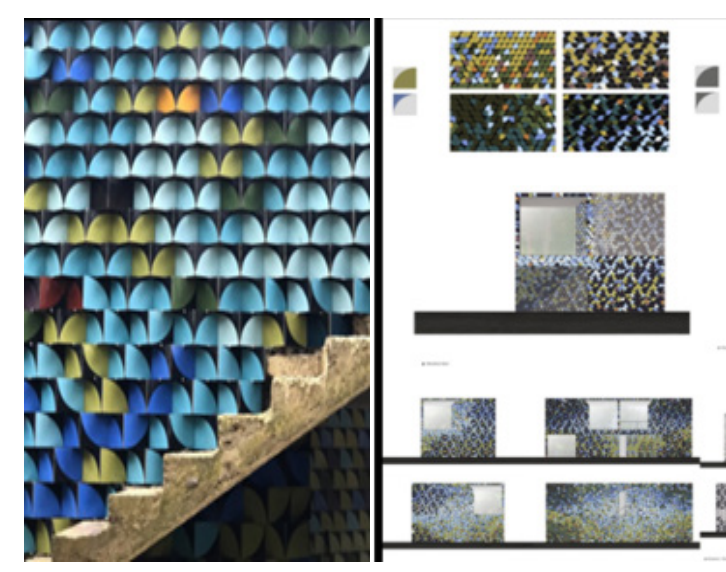
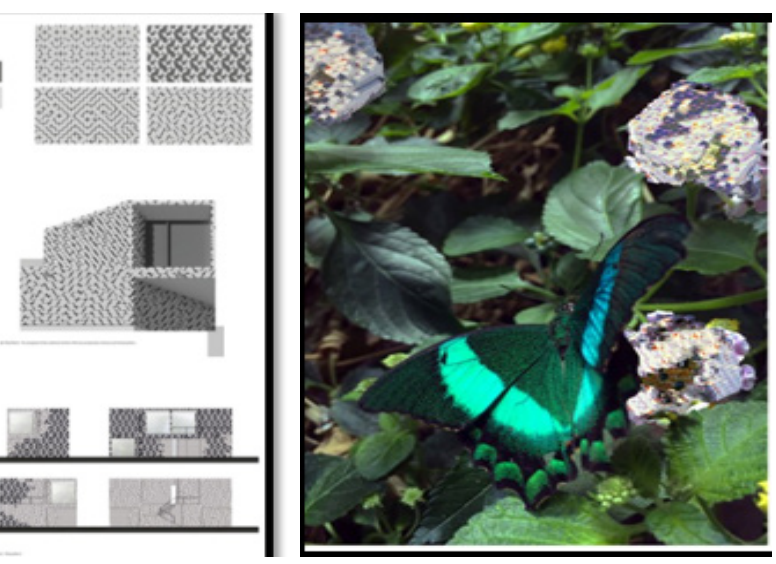

Figure 8. Glitch house facade 
Table 7. Project information

\begin{tabular}{|c|c|}
\hline Project name & Glitch House The \\
\hline Designer & Architect Progressive (Architecture Award) \\
\hline Location & Dominican (Playa Grande) \\
\hline Classification & house \\
\hline Glitch type & Glitch caused by texture \\
\hline Glitch level & 3D level \\
\hline $\begin{array}{c}\text { Glitch } \\
\text { mechanisms }\end{array}$ & $\begin{array}{c}\text { pixilation, Deviation, coding, Dividing the mass, } \\
\text { Complexity, Abstraction, Dividing the mass, } \\
\text { Scaling, Repetition, data manipulation }\end{array}$ \\
\hline
\end{tabular}

\section{Application and Vocabulary Measurement Using the Descriptive Analytical Approach}

This paragraph dealt with the descriptive measurement of the vocabulary in a repetitive table that includes the selected vocabulary, the projects, the repetition values and the percentage of achieving each item in the project using the (Excel 2016) program.

Table 8. Practical application

\begin{tabular}{|c|c|c|c|c|c|c|c|c|c|c|c|}
\hline & \multirow{2}{*}{$\begin{array}{c}\text { Main } \\
\text { Vocabulary }\end{array}$} & \multirow{2}{*}{$\begin{array}{l}\text { Secondary } \\
\text { Vocabulary }\end{array}$} & \multirow{2}{*}{$\begin{array}{l}\text { Sub-vocabul } \\
\text { aries }\end{array}$} & \multirow{2}{*}{\multicolumn{2}{|c|}{ Possible values }} & \multicolumn{3}{|c|}{$\begin{array}{l}\text { Selected } \\
\text { projects }\end{array}$} & \multirow{2}{*}{ 产 } & \multirow{2}{*}{ 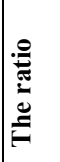 } & \multirow{2}{*}{ : } \\
\hline & & & & & & $\mathbf{A}$ & B & $\mathbf{C}$ & & & \\
\hline \multirow{28}{*}{1} & \multirow{28}{*}{$\begin{array}{c}\text { Tools } \\
\text { generation } \\
\text { glitch shapes }\end{array}$} & \multirow{28}{*}{$\begin{array}{l}\text { Tools of the } \\
\text { in -formed } \\
\text { glitch }\end{array}$} & \multirow{3}{*}{ Decrease } & \multicolumn{2}{|c|}{ Deconstruct items } & 1 & 1 & 0 & 2 & \multirow{3}{*}{$\begin{array}{l}0^{0} \\
0 \\
0 \\
0 \\
0\end{array}$} & \multirow{3}{*}{ 总 } \\
\hline & & & & \multicolumn{2}{|c|}{$\begin{array}{l}\text { Changing the positions of the } \\
\text { geometric shapes }\end{array}$} & 1 & 1 & 0 & 2 & & \\
\hline & & & & \multicolumn{2}{|c|}{ Abstraction of shapes } & 1 & 1 & 0 & 2 & & \\
\hline & & & \multirow{2}{*}{ Deviation } & \multicolumn{2}{|c|}{ Organized deviation } & 0 & 0 & 1 & 1 & \multirow{2}{*}{ 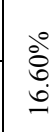 } & \multirow{2}{*}{ 弟芯 } \\
\hline & & & & \multicolumn{2}{|c|}{ Disordered deviation } & 0 & 0 & 0 & 0 & & \\
\hline & & & \multirow{3}{*}{ Translation } & \multicolumn{2}{|c|}{ Line } & 1 & 0 & 0 & 1 & \multirow{3}{*}{$\stackrel{\stackrel{0}{m}}{m} \underset{m}{m}$} & \multirow{3}{*}{ 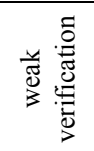 } \\
\hline & & & & \multicolumn{2}{|c|}{ sketch } & 1 & 0 & 0 & 1 & & \\
\hline & & & & \multicolumn{2}{|c|}{ Architectural shape } & 1 & 0 & 0 & 1 & & \\
\hline & & & & & gible & 1 & 1 & 0 & 2 & & ซี \\
\hline & & & & & ngible & 1 & 0 & 0 & 1 & $0^{\circ}$ & 苞 \\
\hline & & & Abstraction & $\begin{array}{r}\text { Extract some } \\
\mathrm{t}\end{array}$ & $\begin{array}{l}\text { ides and remove } \\
\text { rest }\end{array}$ & 1 & 1 & 0 & 2 & @: & $\begin{array}{l}\overrightarrow{0} \\
\stackrel{\overline{0}}{\pi}\end{array}$ \\
\hline & & & & The displa & $\begin{array}{l}\text { ement of some } \\
\text { isses }\end{array}$ & 1 & 0 & 0 & 1 & & 苛 \\
\hline & & & & & ine & 0 & 0 & 0 & 0 & $\therefore$ & 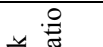 \\
\hline & & & Scaling & & etch & 0 & 0 & 0 & 0 & $\ddot{m}$ & 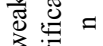 \\
\hline & & & & Archite & tural shape & 1 & 1 & 1 & 3 & $\ddot{m}$ & $\bar{s}$ \\
\hline & & & & Dividing the & hass into squares & 1 & 0 & 1 & 2 & & ธี \\
\hline & & & $\begin{array}{l}\text { Dividing the } \\
\text { mass }\end{array}$ & $\begin{array}{r}\text { Dividing } \\
\text { res }\end{array}$ & $\begin{array}{l}\text { he mass into } \\
\text { angles }\end{array}$ & 1 & 1 & 0 & 2 & $m_{\infty}^{\infty}$ & 氙 \\
\hline & & & & Codin & he picture & 1 & 1 & 1 & 3 & & \\
\hline & & & & Data c & mpression & 1 & 0 & 1 & 2 & & \\
\hline & & & Coding & Correctir & the mistake & 1 & 0 & 1 & 2 & 0 & 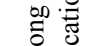 \\
\hline & & & Coding & Encry & the code & 1 & 0 & 1 & 2 & : & $\dot{B}$ \\
\hline & & & & Code the & nes and data & 1 & 0 & 1 & 2 & & \\
\hline & & & & $\begin{array}{r}\text { Shifting fron } \\
\text { int }\end{array}$ & $\begin{array}{l}\text { fragmentation to } \\
\text { gration }\end{array}$ & 1 & 1 & 1 & 3 & & \\
\hline & & & & & $\begin{array}{c}\text { System } \\
\text { properties }\end{array}$ & 1 & 1 & 1 & 3 & & \\
\hline & & & & The level of & $\begin{array}{c}\text { The } \\
\text { environment }\end{array}$ & 1 & 1 & 1 & 3 & $\therefore$ & 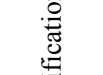 \\
\hline & & & Complexity & $\begin{array}{l}\text { complexity } \\
\text { depends on }\end{array}$ & $\begin{array}{l}\text { The nature of } \\
\text { the interaction } \\
\text { between its } \\
\text { components }\end{array}$ & 1 & 1 & 1 & 3 & $\begin{array}{l}\ddot{m} \\
\ddot{\infty}\end{array}$ & 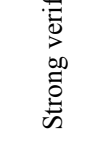 \\
\hline & & & & Complexity & Fractional & 0 & 1 & 0 & 1 & & \\
\hline & & & & $\begin{array}{l}\text { in the shape } \\
\text { system }\end{array}$ & $\begin{array}{l}\text { Non-linear } \\
\text { dynamics }\end{array}$ & 1 & 0 & 1 & 2 & & \\
\hline
\end{tabular}




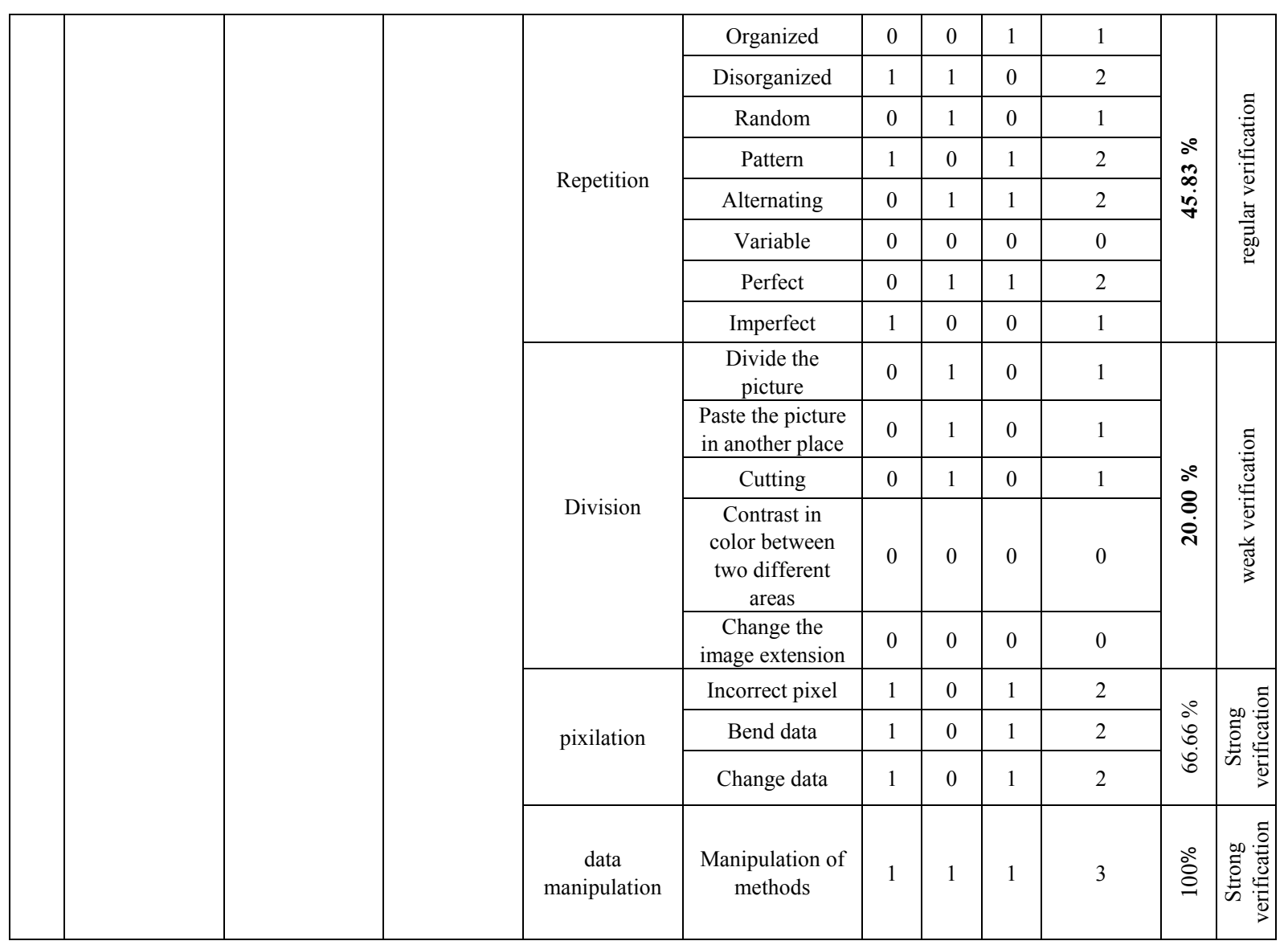

\begin{tabular}{|c|c|c|c|c|c|c|c|c|c|c|}
\hline & \multirow{15}{*}{$\begin{array}{l} \\
\\
\text { The nature } \\
\text { of the glitch } \\
\text { output }\end{array}$} & \multirow{7}{*}{$\begin{array}{l}\text { 1-Features of } \\
\text { glitch output }\end{array}$} & \multirow{2}{*}{\multicolumn{2}{|c|}{$\begin{array}{c}\text { Architectural design with a unique aesthetic } \\
\text { character. } \\
\text { Expresses the cultural background of the } \\
\text { designer. }\end{array}$}} & 1 & 1 & 1 & 3 & \multirow{7}{*}{$\begin{array}{l}\delta^{0} \\
\hat{\alpha} \\
\dot{\delta}\end{array}$} & \multirow{7}{*}{ 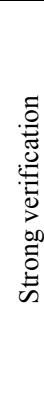 } \\
\hline \multirow{14}{*}{2} & & & & & 1 & 1 & 0 & 2 & & \\
\hline & & & & Domination. & 1 & 0 & 1 & 2 & & \\
\hline & & & Expresse & thetic in an unexpected way. & 1 & 1 & 1 & 3 & & \\
\hline & & & & Transparency & 1 & 0 & 0 & 1 & & \\
\hline & & & & ystemic balance & 1 & 1 & 1 & 3 & & \\
\hline & & & Expand & lers and create new patterns. & 1 & 1 & 1 & 3 & & \\
\hline & & & & Exploration & 1 & 0 & 0 & 1 & & \\
\hline & & & & Systemic balance & 0 & 1 & 1 & 2 & & \\
\hline & & & & $\begin{array}{l}\text { Access to unintended } \\
\text { interactions and areas }\end{array}$ & 0 & 1 & 1 & 2 & & \\
\hline & & & & $\begin{array}{l}\text { Utilizing glitch } \mathrm{s} \text { a solution in } \\
\text { digital design }\end{array}$ & 1 & 1 & 1 & 3 & & \\
\hline & & $\begin{array}{c}\text { Glitch } \\
\text { output goals }\end{array}$ & Designer & $\begin{array}{l}\text { Unobvious and unexpected } \\
\text { product to create attractive } \\
\text { abstract mass }\end{array}$ & 1 & 1 & 1 & 3 & $\begin{array}{l}\circ \\
0 \\
0 \\
\dot{0}\end{array}$ & 苞 \\
\hline & & & & $\begin{array}{c}\text { Dealing with complex spatial } \\
\text { designs }\end{array}$ & 0 & 0 & 1 & 1 & & 离 \\
\hline & & & & $\begin{array}{l}\text { Feeling the architecture } \\
\text { achievement the ability to } \\
\text { survive }\end{array}$ & 0 & 1 & 0 & 1 & & \\
\hline & & & & $\begin{array}{l}\text { Urging artists and designers to } \\
\text { discover glitch and participate } \\
\text { in building its future }\end{array}$ & 1 & 1 & 1 & 3 & & \\
\hline
\end{tabular}


Table 8. Continued

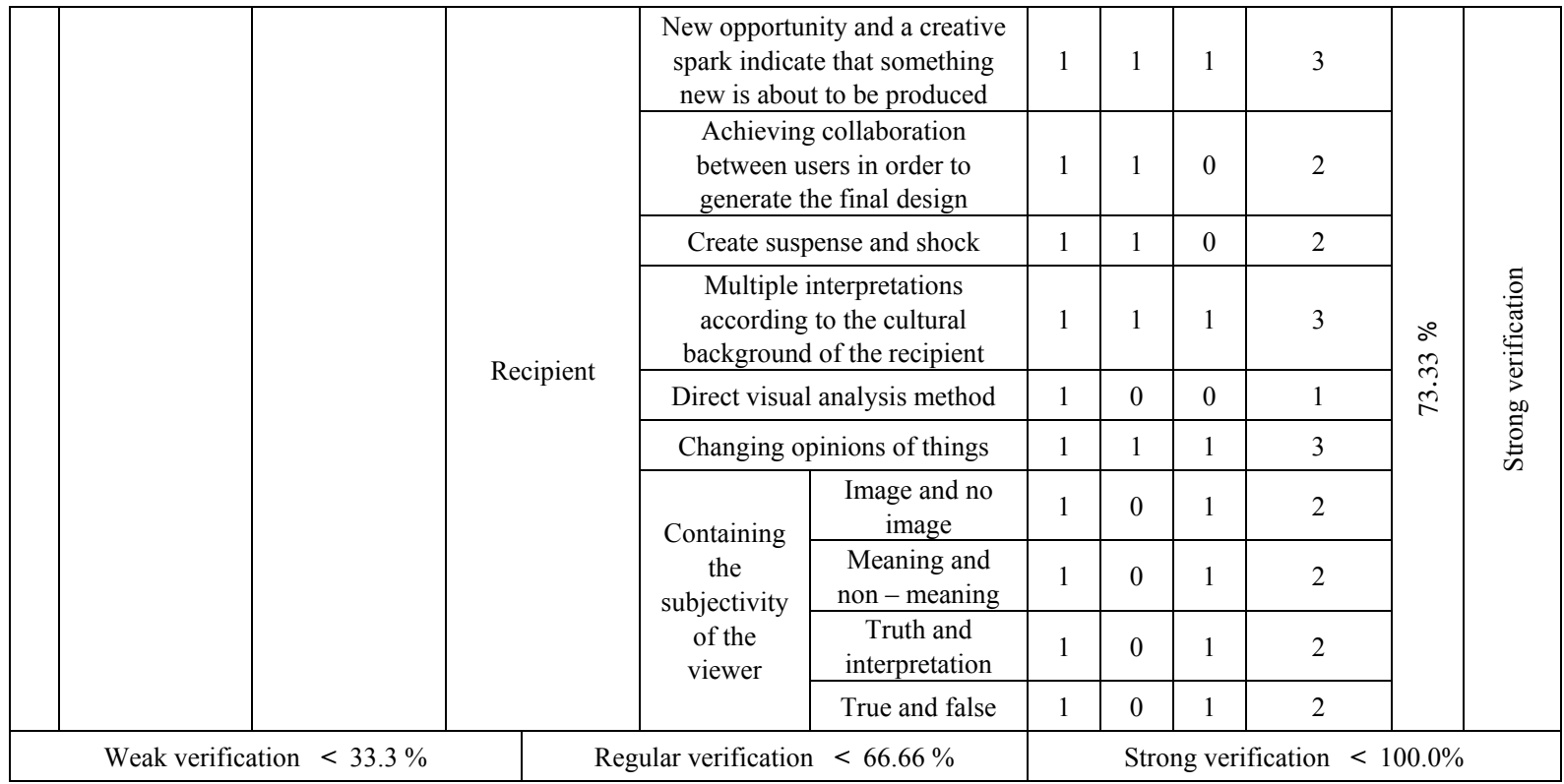

\section{Conclusions}

1. Glitch is an algorithm phenomenon that contains unexpected outcomes to the viewer. It is a short-live system error, like a transient error in a program and it is difficult to discover. This particular term is common in the computing electronics industries and video games as well. Recently it has been invested in the field of architecture.

2. Glitch is a new possibility in digital architecture to deal with complicated spatial designs in a more open manner.

3. The in-formed glitch appears on the three dimensional levels (masses and facade) more than appearing on the two dimensional level (plans), forming new undiscovered shapes that can achieve a clear existence sense of architecture.

4. The data manipulation tool is used to generate digital glitch form depending on manipulation of methods, manipulation with protocols, convert and modify the file, and distorted data entry (Strong verification).

5. The complexity tool is used also to generate digital glitch form depending on the level of complexity in the formal system (Strong verification).

6. The Coding is also used as a tool to generate digital glitch forms by data compression, correcting the mistake, encrypt the code, and code the lines and data (Strong verification).

7. The pixelation is also used as a tool to generate digital glitch forms by adding incorrect pixels or by bending and manipulating the data to form optical illusions (Strong verification).

8. Decrease tool generate digital glitch forms by deconstructing the elements or changing the positions of the geometric shapes and the abstracting them. (Strong verification).

9. Digital glitch forms can be generated also by using dividing mass tool that in crypts images or dividing masses in to squares or rectangles (regular verification).

10. Repetition tool is exploited to generate glitch forms through the process of irregular repetition or through specific pattern in a variable and incomplete way to generate unique and distinct shapes (Regular verification).

11. The design process of glitch forms has no boundaries, so the final outcome has balance, transparency and dominance.

12. Collaboration between designers can be achieved through glitch in order to generate final glitch form by mixing design concept to generate unique products.

13. The unique and unfamiliar glitch form makes the viewer attracted to the final outcome, because of the multiple interpretation achieved by containing the viewer's subjectivity, so glitch is mixture of image and no image, meaning and meaninglessness, truth and interpretation, true and false.

\section{REFERENCES}

[1] Iman Moradi, "Glitch Aesthetics", School of Design Technology, Department of Architecture, the University of Huddersfield, England, PP. 8-11, 2004. https://dokumen.tip s/documents/iman-moradi-glitch-aesthetics-glitch-art.html

[2] Matthew Austin, Gavin Perin, "Drawing the Glitch", Proceedings - Drawing Futures: Speculations in Contemporary Drawing for Art and Architecture, Faculty of 
Design, Architecture and Building, School of Architecture, Sydney, Australia, P.16, 2015. https://www.academia.edu/3 0053162/Drawing the Glitch

[3] Weiss Kopf, C. and Smoijo, D., "! Mediengruppe Bitnik, H3333333k" (accessed 19-10-2021), 2015. Available from https://bitnik.org/h3333333k/

[4] Blaire Haslop, Serdar Aydin, Marc Aurel Schnabel, "Digital Decay", University of Wellington, New Zealand, International Journal of Parallel Emergent and Distributed Systems, Volume 32, Issue sup1: Parallelism in Architecture and Computing Techniques, P.38, 2017, DOI: 10.1080/17445760.2017.1390092

[5] Blaire Haslop, "Digital Decay - glitch architecture", School of Architecture, Victoria University of Wellington, New Zealand, P.209, 2016. https://issuu.com/blairehaslop/docs/b lairehaslop_digitaldecaythesis_red

[6] MATTHEW AUSTIN, G. Perin, "A study between algorithmic design and glitch aesthetics in digital architecture", Proceedings of the 20th International Conference of the Association for Computer-Aided Architectural Design Research in Asia CAADRIA 2, P.14, 2015.https://www.semanticscholar.org/paper/The-other-dig ital\%3A-A-study-between-algorithmic-and-Austin-Perin/d0 3e0b339187fe741ca1adfc9b1713410538c354\#paper-header

[7] Rosa Menkman, "The Glitch Moment (um)" Network notebooks, Amsterdam, Netherlands, ISBN/EAN 978-90-816021-6-7, p.27-36, 2011 https://issuu.com/institut eofnetworkcultures/docs/glitchmomentum

[8] Heijer, Eelco den, "Evolving Glitch Art", Objectivation B.V, Conference: Evo MUSART 2013, LNCS 7834 At: Vienna, Austria, PP. 1-13, DOI: 10.1007/978-3-642-36955110
[9] Vuillemot, Huron, "Glitches as a Generative Design Process", university of Lyon, France Conference: 2017 IEEE VIS Arts Program (VISAP), October 2017, P.3-5, DOI: 10.1109 /VISAP.2017.8282377

[10] Sorapoj Techakraisri, "MahaNakhon: A Pixelated Punctuation Mark on the Bangkok Skyline" Journal of CTBUH Research paper, the future of tall: A selection of written works on current skyscraper innovations, Conference proceeding, P.15, 2015. https://global.ctbuh.org /resources/papers/download/2399-mahanakhon-a-pixelatedpunctuation-mark-on-the-bangkok-skyline.pdf

[11] Buro Ole Scheeren, "Thailand's Tallest Skyscraper Pixel Tower or Mahanakhon", Themindcircle, https://themindcirc le.com/bangkok-tallest-skyscraper-building-mahanakhon-th ailand/ (accessedSep. 23, 2021).

[12] Darth Vader, Thailand's New Tallest Building Doesn't Actually Look Real, hipsthetic, https://www.hipsthetic.com /thailands-new-tallest-building-doesnt-actually-look-real/, (accessed Sep. 20, 2021).

[13] Colin Fournier, "In Praise of the Glitch: WAA's Yinchuan Contemporary Art Museum", arch daily, https://www.archdaily.com/780006/in-praise-of-the-glitchwaas-yinchuan-contemporary-art-museum?ad_medium=gal lery (accessed Sep. 21, 2021).

[14] Ian Volner, "Glitch House", architect magazine, https://www.architectmagazine.com/project-gallery/glitch-h ouse_o (accessed Sep. 25, 2021).

[15] Young project, "Glitch House" Dominican Republic, http://young-projects.com/glitch-house (accessed Sep. 26, 2021). 